\title{
An extendable modular endoprosthetic system for bone tumour management in the leg
}

\author{
G.J. Verkerke*, H. Schraffordt Koops*, R.P.H. Veth*, H.H. van den \\ Kroonenberg ${ }^{\dagger}$, H.J. Grootenboer ${ }^{\dagger}$, H.K.L. Nielsen* ${ }^{*}$ J. Oldhoff* and A. Postma* \\ *Departments of Surgical Oncology and Orthopaedic Surgery, Groningen University \\ Hospital, Groningen, The Netherlands, and 'Faculty of Mechanical Engineering, Univer- \\ sity of Twente, Enschede, The Netherlands
}

Received June 1989, accepted September 1989

\begin{abstract}
A modular endoprosthetic system has been developed at the Groningen University Hospital and the University of Twente. The system can bridge a defect resulting from the resection of a malignant bone tumour which has deoeloped around the knee joint of a child. Since the other healthy leg continues to grow, the system includes an element whose length can be adjusted non-invasively by using an external magnetic field. In addition to this lengthening element, there are one hip and two knee components, connectors of various lengths, and fuxation elements. The paper describes the elements of the modular endoprosthetic system. Tables are created by means of which the elemental composition of such an endoprosthesis can be determined for each individual patient.
\end{abstract}

Keywords: Endoprosthesis, tumour, modular system, limb salvage

\section{INTRODUCTION}

In young children, a malignant tumour may develop in the femur, usually at the distal metaphysis, and up to about ten years ago amputation of the leg was the only treatment. Nowadays it is often possible to save the leg, especially in cases where a good reaction is observed after chemotherapy. Resection of the affected region can be followed by reconstruction with the aid of an endoprosthesis ${ }^{15}$. This method has the drawback that, in time, a difference in leg length will occur, since the distal femoral and the proximal tibial epiphysis are also removed. For this reason a new endoprosthetic system has been developed at the Groningen University Hospital and the University of Twente to bridge the bony defect. This system is special in that it contains an element whose length can be adjusted non-invasively, so that the growth of the other healthy leg can be matched.

There are three basic features regarding the composition of an existing endoprosthetic system.

1. There is a restricted number of sizes and types of ready-made, standard prosthesis.

2. There is one standard concept. For each patient a custom-made prosthesis is produced by adapting the sizes of the concept prosthesis.

3. The system consists of several ready-made modules, each with a restricted number of sizes and types.

A surgeon who uses a ready-made, standard prosthesis has a limited choice of types and must, to some

Correspondence and reprint requests to G.J. Verkerke, University of Twente, Faculty of Mechanical Engineering (WB/OW), P.O. Box 217, 7500 AE Enschede, The Netherlands extent, increase the necessary bone resection to suit the nearest available size of replacement. Improving this would mean a considerable investment for a large stock of endoprostheses ${ }^{6}$.

The advantage of implanting a custom-made prosthesis is the adaption of the replacement to the patient instead of the reverse. However, manufacture of custom-made prostheses used to take some time, generally two to eight weeks; however, this situation may be improved by utilizing computer-aided design and manufacturing techniques and by using pre-fabricated modules to be assembled by the manufacturer.

A logical further improvement is to assemble a modular endoprosthesis before the operation. Since an endoprosthesis consists of various modules, many different endoprostheses can be assembled in spite of the limited number of component modules 7,8 . An extra advantage is that a modular endoprosthesis allows for the replacement of one component by another in case of failure or merely to adapt the endoprosthesis type to altered needs of the patient. Existing fixations to bone can remain unimpaired and surgical trauma is minimized.

The endoprosthetic system which we have developed is of the modular type and contains the following elements (Figure 1):

- lengthening elements of various lengths

- two knee components

- a hip component with various heads and necks

- connectors of various lengths

- bone-prosthesis connections (fixation elements).

With these components, an endoprosthesis for each patient can be assembled, its composition depending 


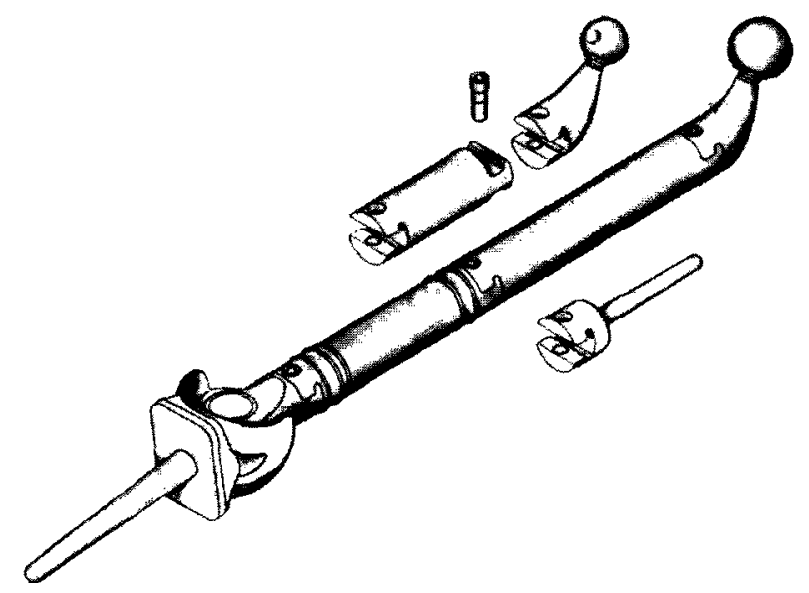

Figure 1 Modular endoprosthetic system

on the length of the resection and on the identity of the resected bone itself (femur or tibia). All components will be described briefly.

To link the different modules, a universal connection was constructed and tested in vitro ${ }^{9}$ with a single torsional loading of $200 \mathrm{Nm}$ in both directions, a torsional fatigue loading of $28 \mathrm{Nm}$ during $10^{6}$ cycles at a frequency of $10 \mathrm{~Hz}$, a single four-point bending load of $320 \mathrm{Nm}$ in four perpendicular directions, and bending fatigue loading during $10^{6}$ cycles between 23 and $72 \mathrm{Nm}$ at a frequency of $10 \mathrm{~Hz}$. No permanent deformation was observed after the tests. Nondestructive testing did not reveal any cracks.

The universal connection was also tested in vivo ${ }^{10}$ in combination with a lengthening element. Three animal experiments with two prototypes were performed. The prototypes were implanted in the tibia of goats for 1.5, 2 and 4 months. After each period, the two parts of the universal connection were found to be firmly attached to each other. No wear marks were visible, and disassembly was easy.

The modular endoprosthetic system can be used after resection of the proximal tibia, the distal, proximal or entire femur. In order to decide the components from which an endoprosthesis should be assembled in each situation, a number of starting points were defined. Guidelines for the composition of an endoprosthesis were then determined.

\section{COMPONENTS}

\section{Lengthening element}

The lengthening element is adjusted non-invasively to follow the growth of the other normal leg. This is achieved by using an external rotating magnetic field which causes rotation of a small permanent magnet in the prosthesis. The magnet drives a motion screw via a gearbox. This screw forces two telescopic tubes apart. The polygonal shape of the inner tube prevents rotary movement between the tubes. To shield the lengthening element from moisture a bellows made of silicone rubber was glued to the lengthening element. The final prototype of this lengthening element (Figure 2) was tested in vitro ${ }^{11}$ as well as in vivo ${ }^{10}$.
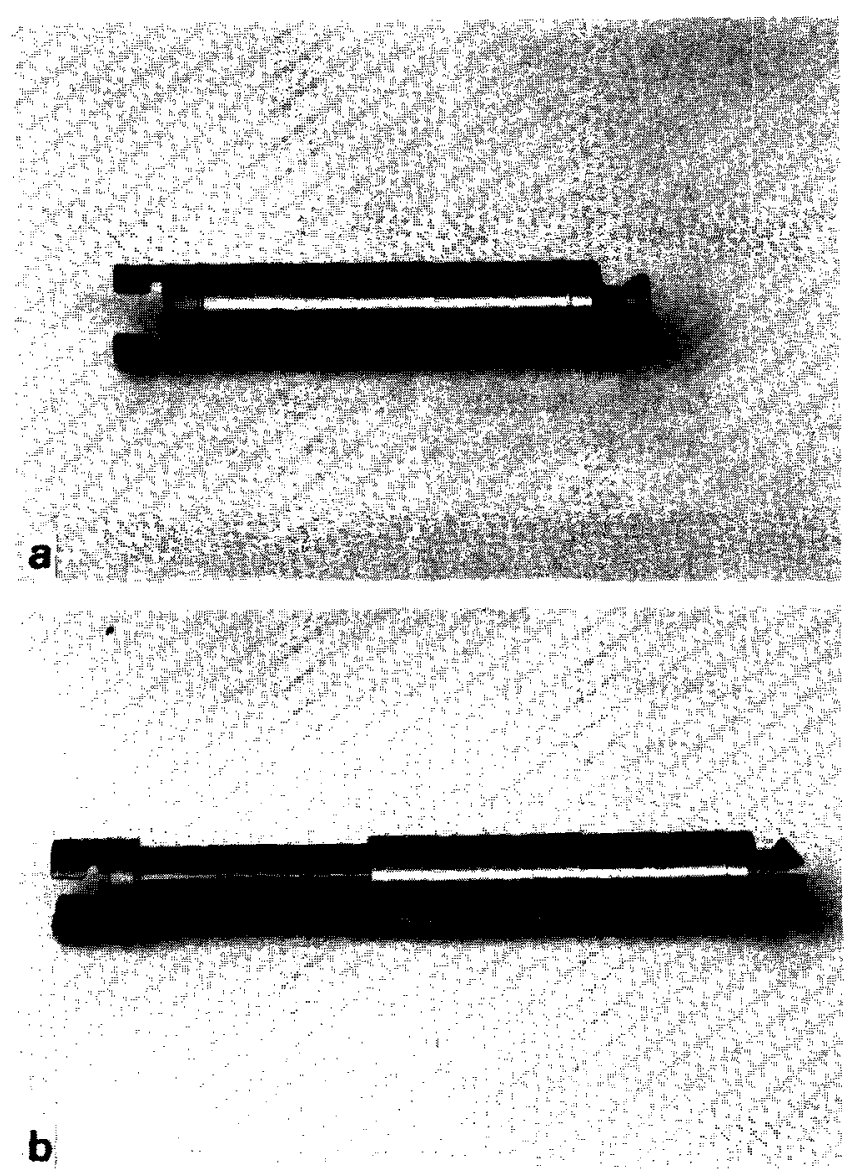

Figure 2 Lengthening element without bellows a, before and b, after full extension

To check the effectiveness of the power supply, the lengthening element was loaded with $450 \mathrm{~N}, 30 \mathrm{~mm}$ eccentric acting, and lengthened by a magnetic field of $0.02 \mathrm{~T}$. Extension appeared to be possible even after five days of inactivity. Since during use in patients forces of $200 \mathrm{~N}$ at most are expected, this test proved the satisfactory functioning of the lengthening element. The outer and the inner tube were tested for strength in the same way as the universal connection; no permanent deformation was observed. In order to check whether the bellows and glue bonding were watertight and if the reduced pressure (caused by an increasing volume during elongation of the lengthening element) was equalized by gas diffusion, a prototype was immersed in aerated Ringer's solution and lengthened in steps of $5 \mathrm{~mm}$ while measuring the pressure in the model. The bellows and glue bonding proved to be watertight: after four days no moisture had infiltrated the prosthesis. The lowering of the pressure caused by $5 \mathrm{~mm}$ lengthening had decreased by $90 \%$ in 19 hours.

To check the complete lengthening element with bellows and universal connection, three prototypes were implanted in the tibia of goats. The total extension of $28 \mathrm{~mm}$ was reached after seven weekly extensions of $4 \mathrm{~mm}$. All extensions resulted in $4 \mathrm{~mm}$ elongations, in spite of an ectopic bone bridge between the two bone segments which had bridged the prosthesis completely. The bellows was intact and had protected the prosthesis from moisture. 


\section{Knee components}

The two knee components used in the modular endoprosthetic system are derived from an existing semi-constrained knee prosthesis, made from a $\mathrm{Co}-$ $\mathrm{Cr}$-Mo alloy. In one knee component the tibial stem is replaced by the universal connection. The tibial part of this knee component is $20 \mathrm{~mm}$ in length. In the other knee component the femoral stem is replaced by the universal connection. The femoral part of this knee component is $55 \mathrm{~mm}$ long. Both components are obtainable in a left or right configuration.

\section{Hip component}

The hip component, used in the modular endopros thetic system, is derived from an existing hip prosthesis and can be provided with various heads and necks of different materials and sizes. Instead of a stem, this hip prosthesis is provided with the universal connection. The hip component is $70 \mathrm{~mm}$ long and obtainable in a left or right configuration. For acetabular replacement, any system (even bipolar) with appropriate cup diameters can be used.

\section{Connectors}

The connectors are composed of a hollow shaft with two lids, which are provided with the universal connection. They are manufactured in two parts, the shaft with one lid, and the other lid separately. In order to fasten the two parts of the connector, they may be welded together. Both TIG-welding and plasma arc-welding were tried ${ }^{12}$. Plasma arc-welding was preferred because of the small size of the heataffected zone. Two plasma arc-welded test pieces were subjected to the loading tests as described previously. Both the weld and the shaft were tested and neither showed any permanent deformation. A non-destructive test did not show any cracks. A hole was made in one lid to allow free movement of the protective gas used during the welding process. After the welding process was completed, the hole was closed by a UHMW-PE plug.

\section{Bone-prosthesis connection}

The endoprosthesis, assembled from the modular endoprosthetic system, is fixed to the remaining part of the femur with a custom-made, press-fit fixation. A stem, on which the contours of the bone are transposed, is placed in the medullary canal and extracor- tical side plates with unicortical screws provide for the primary rotation stability. The fixation to the remaining part of the tibia is performed by a stem cemented in the medullary canal. At the Groningen University Hospital these fixations have been applied to the fixation of tumour prostheses ${ }^{13,14}$. After an observation period from two to eight years no failure was observed.

\section{COUPLE CORROSION}

Most elements of the modular endoprosthetic system are made of $\mathrm{Ti}-\mathrm{A} 6-4 \mathrm{~V}$. When two elements are manufactured from different material, stocks their composition, although restricted to limits according to ASTM-F136, could differ as much as to cause couple corrosion. Coupling $\mathrm{Ti}-6 \mathrm{Al}-4 \mathrm{~V}$ elements to the Co-Cr-Mo knee component or to $\mathrm{Co}-\mathrm{Cr}-\mathrm{Mo}$ heads of the femur component could also cause couple corrosion. Rostoker et al. ${ }^{15}$ have performed an investigation on couple corrosion. Potential corrosion couples were formed, amongst others, between Ti$6 \mathrm{Al}-4 \mathrm{~V}$ and $316 \mathrm{~L}$ stainless steel, cast $\mathrm{Co}-\mathrm{Cr}-\mathrm{Mo}$ alloy, $\mathrm{Ti}-6 \mathrm{Al}-4 \mathrm{~V}$ itself, a $\mathrm{Co}-\mathrm{Ni}-\mathrm{Cr}-\mathrm{Mo}$ alloy and graphite. The couples were tested in vitro for 100 days in a $1 \%$ saline solution at a temperature of $37^{\circ} \mathrm{C}$. It appeared that no combination except $316 \mathrm{~L}$ with $\mathrm{Ti}-6 \mathrm{~A} 1-4 \mathrm{~V}$ created a corrosion problem. By comparing the results of other couples with results of long term in vivo experiments, it is probable that the in vitro experiments of 100 days are comparable with in vivo experiments of at least six years. This research would indicate that couple corrosion among elements of the modular endoprosthetic system is very unlikely to occur.

\section{STARTING POINTS FOR THE COMPOSITION OF THE MODULAR SYSTEM}

(1) The endoprosthetic system has to be suitable for children from age ten years with a tumour in the femur, the knee or the proximal tibia.

(2) At implantation, the prosthesis may be $20 \mathrm{~mm}$ longer than the resected bone, without compromising the function of the neurovascular bundle. Also, a permanent difference in leg length of $20 \mathrm{~mm}$ at most is permitted. Therefore, the necessary lengthening capacity may be reduced by $40 \mathrm{~mm}$ at most. Consequently, for tumours in the proximal femur (maximum further length growth $38 \mathrm{~mm}$, (Figure 3), no lengthening element is necessary.

(3) In tumours of the distal femur, the knee or the

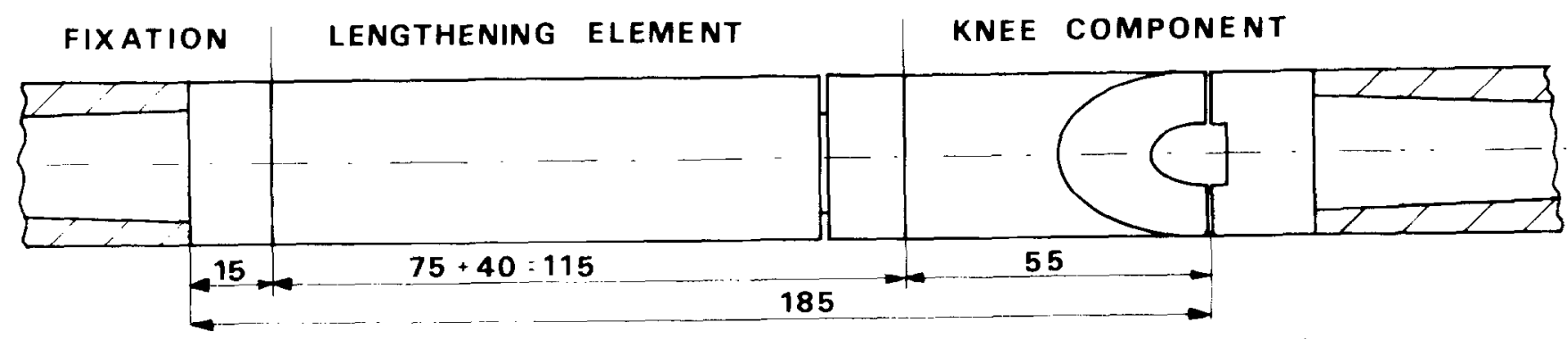

Figure 3 Modular endoprosthetic system to be used after a resection of the distal femur (dimensions in $\mathrm{mm}$ ) 
Table 1 Extra growth (mm) of the femur and tibia of the healthy leg (with regard to the affected leg) as measured on healthy children $(\min =5$ percentile, mean $=50$ percentile, $\max =95$ percentile).

\begin{tabular}{|c|c|c|c|c|c|c|c|c|c|c|}
\hline \multirow{2}{*}{$\begin{array}{l}\text { Age }(y r) \\
\text { Male }\end{array}$} & \multirow[b]{2}{*}{ Female } & \multicolumn{2}{|c|}{$\begin{array}{l}\text { Distal } \\
\text { growth femur }\end{array}$} & \multirow[b]{2}{*}{$\max$} & \multicolumn{3}{|c|}{$\begin{array}{l}\text { Proximal } \\
\text { growth tibia }\end{array}$} & \multicolumn{2}{|c|}{$\begin{array}{l}\text { Total } \\
\text { growth femur }\end{array}$} & \multirow[b]{2}{*}{$\max$} \\
\hline & & $\min$ & mean & & $\min$ & mean & $\max$ & $\min$ & mean & \\
\hline 10 & 8 & 59 & 76 & 93 & 39 & 50 & 61 & 84 & 108 & 132 \\
\hline 11 & 9 & 46 & 63 & 80 & 30 & 41 & 52 & 65 & 89 & 113 \\
\hline 12 & 10 & 30 & 49 & 69 & 18 & 31 & 44 & 42 & 70 & 97 \\
\hline 13 & 11 & 12 & 34 & 56 & 5 & 20 & 36 & 17 & 48 & 78 \\
\hline 14 & 12 & 0 & 20 & 40 & 0 & 11 & 24 & 0 & 28 & 56 \\
\hline
\end{tabular}

proximal tibia, the distal femoral and the proximal tibial and fibular epiphyses are always resected or deactivated.

(4) The growth of the normal leg compared with the affected leg can be determined with the aid of growth tables ${ }^{16}$. These list, by age, the increasing lengths of femur and tibia until the end of the growth period, with their deviations. A $2.5 \%$ positive correction is applied to the growth length to adjust the data to present-day average heights ${ }^{17}$. After resection of the distal femoral epiphysis, the extra growth of the normal leg amounts to $71 \%$ of the growth of the femur; after resection of the proximal tibial epiphysis the extra growth of the normal leg amounts to $57 \%$ of the growth of the tibia. The extra growths of femur and tibia are listed in Table 7.

(5) The length of a lengthening element equals the lengthening capacity plus $75 \mathrm{~mm}$, a boneprosthesis connection is $15 \mathrm{~mm}$ long.

(6) In order to keep the number of lengthening elements and connectors within reasonable limits, it was decided to include three lengthening elements with capacities of 40,60 , and $80 \mathrm{~mm}$ and five connectors with lengths of $20,40,60,80$ and $100 \mathrm{~mm}$.

With these starting points, guidelines for the composition of an endoprosthesis were produced.

\section{ENDOPROSTHESIS COMPOSITION}

\section{Endoprosthesis composition after resection of the distal femur}

The endoprosthesis to be implanted after a resection of $165 \mathrm{~mm}$ of the distal femur is shown in Figure 3. The lengthening capacity of the lengthening element is $40 \mathrm{~mm}$. After implantation of the endoprosthesis
Table 2 Composition of the endoprosthetic system after resection of the distal femur (dimensions in $\mathrm{mm}$ )

\begin{tabular}{lll}
\hline Resection length & $\begin{array}{l}\text { Lengthening capacity } \\
\text { of lengthening } \\
\text { element }\end{array}$ & connector \\
\hline 185 & 40 & - \\
205 & 60 & - \\
225 & 80 & - \\
245 & 80 & 20 \\
265 & 80 & 60 \\
285 & 80 & 0 \\
\hline
\end{tabular}

the femur is $20 \mathrm{~mm}$ longer, which is acceptable, but it does involve a necessary temporary heightening of the healthy leg by $20 \mathrm{~mm}$. The permissible subsequent growth of the healthy leg has increased to 60 $\mathrm{mm}$. If the resection length exceeds $165 \mathrm{~mm}$, the endoprosthesis can be adjusted by implanting a longer lengthening element (with 20 or $40 \mathrm{~mm}$ more lengthening capacity) and, in some cases, an extra connector in the femur. The composition of the endoprosthetic system for all resection lengths can be determined from Table 2 .

\section{Endoprosthesis composition after resection of the proximal tibia}

The endoprosthesis to be implanted after a resection of $130 \mathrm{~mm}$ of the proximal tibia is shown in Figure 4. The lengthening capacity of the lengthening element is $40 \mathrm{~mm}$. As Figure 4 shows, the tibia is $20 \mathrm{~mm}$ longer after implantation of the endoprosthesis, which is acceptable. This increases the permissible growth of the healthy leg to $60 \mathrm{~mm}$. In case of a resection length in excess of $130 \mathrm{~mm}$, the endoprosthesis may be adjusted by implanting a lengthening element 20 or $40 \mathrm{~mm}$ longer and, in some cases, an extra connector in the tibia. The composition of the endoprosthesis for all resection lengths can be determined from Table 3.

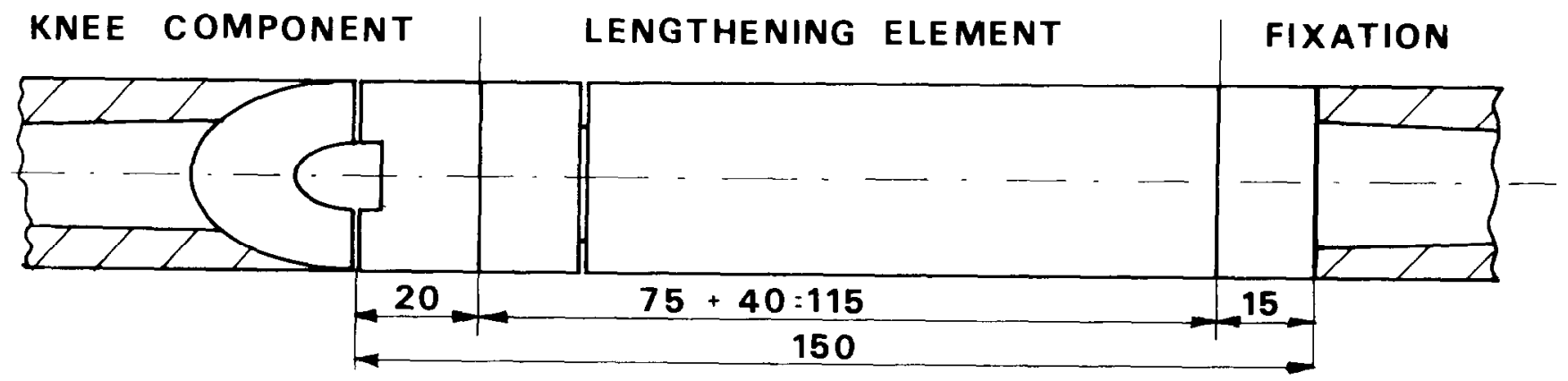

Figure 4 Modular endoprosthetic system to be used after resection of the proximal tibia (dimensions in $\mathrm{mm}$ ) 


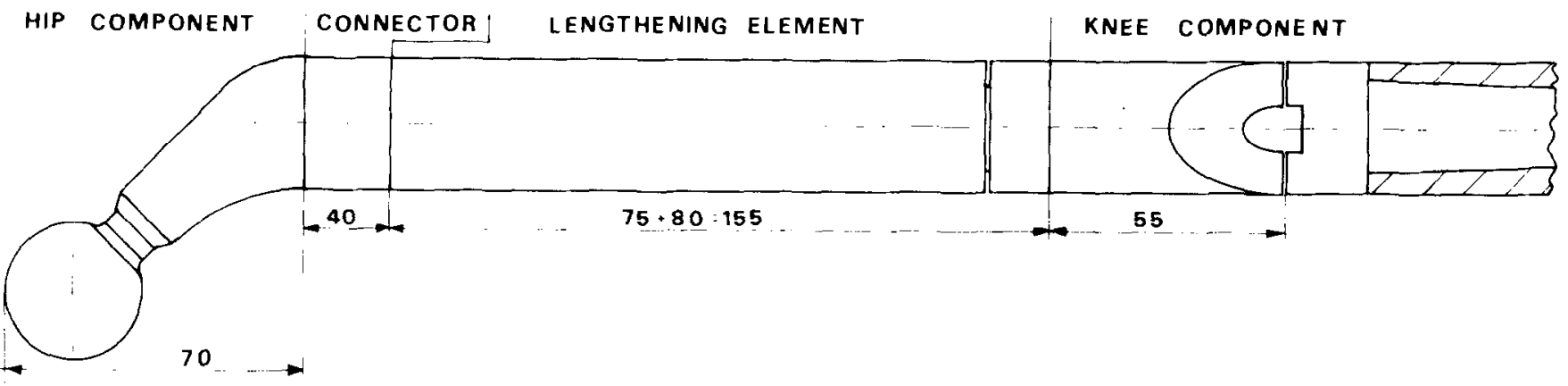

Figure 5 Modular endoprosthetic system to be used after resection of the entire femur (dimensions in $\mathrm{mm}$ )

Table 3 Composition of the endoprosthetic system after resection of the proximal tibia (dimensions in $\mathrm{mm}$ )

\begin{tabular}{lll}
\hline Resection length & $\begin{array}{l}\text { Lengthening capacity } \\
\text { of lengthening } \\
\text { element }\end{array}$ & $\begin{array}{l}\text { Length of tibial } \\
\text { connector }\end{array}$ \\
\hline 130 & 40 & - \\
150 & 60 & - \\
170 & 80 & - \\
190 & 80 & 20 \\
210 & 80 & 40 \\
230 & 80 & 60 \\
\hline
\end{tabular}

Table 4 Composition of the endoprosthetic system after resection of the entire fernur

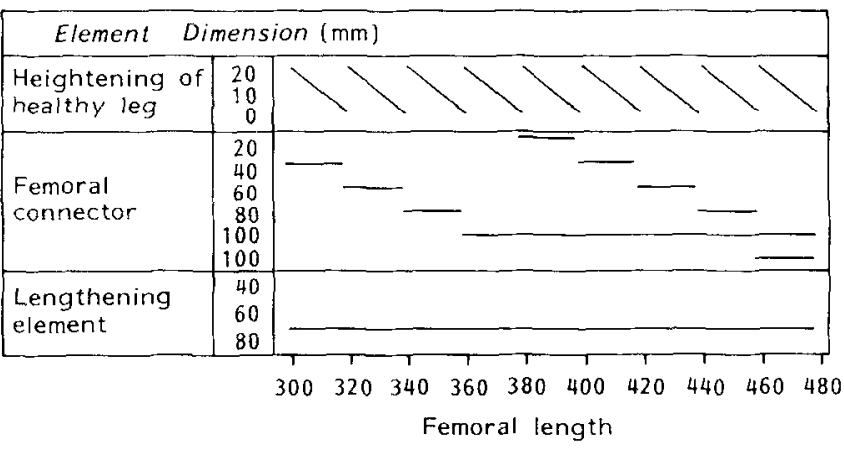

\section{Endoprosthesis composition after resection of the entire femur}

The composition of the endoprosthesis implanted after resection of a femur $300 \mathrm{~mm}$ long is presented in Figure 5. The capacity of the lengthening element is $80 \mathrm{~mm}$. After implantation of the endoprosthesis the femur is $20 \mathrm{~mm}$ longer, which is acceptable, but it does involve a necessary temporary heightening of the healthy leg by $20 \mathrm{~mm}$. The allowable growth of the healthy leg is then increased to $100 \mathrm{~mm}$. In the case of a longer femur between 300 and $320 \mathrm{~mm}$, implantation of a larger connector is not yet possible. The resected length in excess of $185 \mathrm{~mm}$ must therefore be compensated by decreasing the heightening of the healthy leg, which reduces the growth of the healthy leg that can subsequently be permitted. Table 4 presents the composition of the endoprosthesis system for all femur lengths. With the hip component, the system is also suitable for use after resection of the proximal femur (in combination with a bone-prosthesis connection and, if necessary, a connector). In this case, no lengthening element is required.

\section{CONCLUSIONS}

The modular endoprosthetic system consists of boneprosthesis connections, two semiconstrained knee components (in both left and right configurations), lengthening elements (with capacities of 40,60 and 80 $\mathrm{mm}$ respectively), connectors $(20,40,60,80$ and 100 $\mathrm{mm}$ in length), and a hip component with various heads and necks (in left and right congiruations) all allowing a correctly sized endoprosthesis to be assembled for boys from age ten and girls from age eight in whom a part of the tibia or femur has been resected as a treatment for a malignant bone tumour. The modular endoprosthetic system described here will be clinically evaluated at the Groningen University Hospital.

\section{REFERENCES}

1. Eckardt JJ, Eilber FR, Kabo JM, Mirra JM. Kinematic rotating hinge knee-distal femoral replacement. In: Enneking WF, ed. Limb Salvage in Musculoskeletal Oncology. New York: Churchill Livingstone, 1987: 392-409.

2. Lane JM, Spindler, K, Duane K, Glasser DB, Healey JH, Kroll M. Otis JC, Burstein A. Large segmental reconstruction about the knee: Function and prosthetic performance. In: Enneking WF, ed. Limb Salvage in Musculoskeletal Oncology. New York: Churchill Livingstone, 1987: 194-7.

3. Nielsen HKL, Veth RPH, Oldhoff J, Schraffordt Koops H, Kamps WA, Postma A, Göeken LNH, Hartel RM, Krieken FM van. Functional results of prosthetic replacement in patients with primary tumours of the distal femur. In: Enneking WF, ed. Limb Salvage in Musculoskeletal Oncology. New York: Churchill Livingstone, 1987: 424-6.

4. Sim FH, Chao EYS. Segmental prosthetic replacement of the knee after tumour resection. In: Enneking WF, ed. Limb Salvage in Musculoskeletal Oncology. New York: Churchill Livingstone, 1987: 379-88.

5. Veth RPH, Nielsen HKL, Oldhoff J, Schraffordt Koops H, Postma A, Kamps W, Heeten GJ van, Hartel RM, Krieken FM van, Göeken LNH, Oosterhuis JW. The treatment of primary tumours of the femur with chemotherapy (if indicated), resection and reconstruction with an endoprosthesis. J Surg Oncol 1985; 30: 252-8.

6. Chao EYS, Sim FH. Modular types of tumour endoprostheses for limb salvage. In: Enneking WF, ed. Limb Salvage in Musculoskeletal Oncology. New York: Churchill Livingstone, 1987: 198-206.

7. Chao EYS, Sim FH. Modular design system for tumour prostheses. In: Kotz R, ed. Proc of the 2nd International Workshop on the Design and Application of Tumour Prostheses. Vienna: Egermann, 1983: 207-13.

8. Kotz R. A modular femur and tibia reconstruction system. In: Kotz R. ed. Proc of the 2 nd International Workshop on the 
Design and Application of Tumour Prostheses. Vienna: Egermann, 1983: 223-6.

9. Verkerke GJ, Krieken FM van, Nielsen HKL, Oldhoff J, Schraffordt Koops H, Veth RPH, Postma A, Goëken LNH, Kroonenberg HH van den, Grootenboer HJ. The development of a connection between the modules of a modular femur endoprosthesis. In: Yamamuro T, ed. New Developments for Limb Salvage in Musculoskeletal Oncology. Kyoto: Springer-Verlag, 1987: 649-51.

10. Verkerke GJ, Kroonenberg $\mathrm{HH}$ van den, Grootenmboer HJ, Veth RPH, Schraffordt Koops H, Nielsen HKL, Oldhoff J. In vitro and in vivo experiments of a lengthening element for a modular femur endoprosthetic system. In: Limb Salvage in Musculoskeletal Oncology. 1989, (in press).

11. Verkerke GJ, Veth RPH, Srhraffordt Koops H, Kroonenberg $\mathrm{HH}$ van den, Grootenboer $\mathrm{HJ}$, Nielsen HKL, Oldhoff J. A lengthening element for a modular femur endoprosthetic system. In: Transactions of the 35th annual meeting of the Orthopaedic Research Society. Las Vegas: Orthopaedic Research Society, 1989: 494.

12. Krieken FM van. Methodical Design of a Modular Femur Endoprosthesis (PhD Thesis). Enschede, University of
Twente: 1987.

13. Veth RPH, Nielsen HKL, Oldhoff J, Schraffordt Koops H, Metha D, Postma L, Göeken LNH, Oosterhuis JW, Verkerke B. Resection of tumour of the pelvis and proximal femur. Evaluation of survival, local recurrence and function. In: Yamamuro T, ed. Nere developments for Limb Salvage in Musculoskeletal Oncology. Kyoto: SpringerVerlag, 1987: 419-24.

14. Veth RPH, Nielsen, HKL, Oldhoff J, Schraffordt Koops H, Metha D, Oosterhuis JW, Kamps WA, Göeken LNH. Mega prostheses in the treatment of primary malignant and metastatic tumours in the hip region. $J$ Surg Oncol 1989; 40: 214-18.

15. Rostoker W, Pretzel CW, Galante JO. Couple corrosion among alloys for skeletal prostheses. $J$ Biomed Mat Res 1974; 8: 407-19.

16. Anderson M, Green WT, Messner MB. Growth and predictions of growth in the lower extremities. J Bone Joint Surg 1963; 45A: 1-14.

17. Molenbroek JFM, Dirken JM. Dutch body measures (DINED-table). Internal report, Delft University of Technology, Delft, The Netherlands, 1984. 